\title{
Rotational molding: A review of the models and materials
}

\author{
K. O. Ogila*, M. Shao, W. Yang, J. Tan \\ Ying Lan Laboratory of Advanced Polymer Processing, College of Mechanical and Electrical Engineering, Beijing \\ University of Chemical Technology, 15 North Ring Road Beijing, 100029 Beijing, China
}

Received 2 March 2017; accepted in revised form 2 May 2017

\begin{abstract}
This article surveys recent and not so recent literature in the field of rotational molding. The mechanisms of heat transfer, sintering and bubble removal are evaluated; as are degradation and dimensional stability. The parameters that affect the surface finish are highlighted and a number of the control systems available to the rotational molding process are mentioned. Improvements in molds and machinery, and the extent to which they reduce cycle times are also described. Finally, the range of materials available to the rotational molding process is examined and recent developments are highlighted. Of particular interest is the rotational molding of liquid polymer systems; which are shown to possess great potential for fulfilling many of rotational molding's surface quality requirements while simultaneously reducing cycle times.
\end{abstract}

Keywords: processing technologies, rotational molding, surface finish, process control

\section{Introduction}

Rotational molding (RM) is a polymer processing technique that possesses a number of advantages such as lower residual stresses in parts, simpler machinery and molds, and the ability to produce single or double walled components with complex geometries and varied sizes. RM is characterized by the placement of polymer resin in one half of a divided mold, subsequent closure of the mold, followed by the simultaneous application of bi-axial rotation and heat. The resin is deposited on the mold wall where it forms a dense unified layer [1]. When densification is completed, the mold is moved to the cooling station as rotation continues. Once demolding temperatures are achieved, the finished part is removed from the mold (Figure 1). Heating of the mold can be achieved using a number of means including: convective heat transfer through air inside an oven, direct heating by gas combustion, electric heating elements [2], microwave heating [3] and recently by solar energy [4]. At the cooling station, demolding temperatures are achieved either by rotating the mold in quiescent air, directing streams of cold air and towards it, atomized water evaporative cooling [5] or by using internal cooling mechanisms [6]. RM, unlike most polymer processing techniques, is a zero shear process. Deposition of the polymer resin onto the mold wall occurs gradually without the action of any external force. The majority of resins used in RM are thermoplastic powders; of which polyethylene (PE) makes up about $90 \%$ [1]. RM is increasingly becoming the preferred method for manufacturing large parts with high structural requirements; including boats, water and chemical receptacles, pallets and even wind turbine blades [7].

RMs potential as a manufacturing process for polymeric components is limited by a number of concerns that include difficulties in process control, a narrow range of applicable polymers, long cycle times and poor surface finish. The current review analyses these limitations and possible solutions to them. The conclusion discusses and summarizes the findings of the study. 

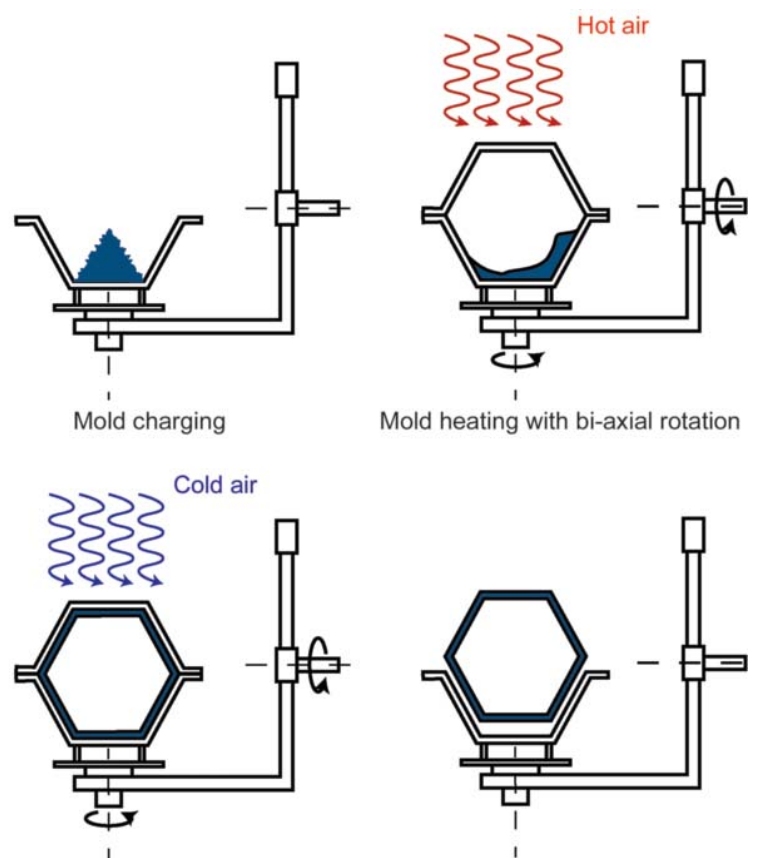

Mold cooling with bi-axial rotation

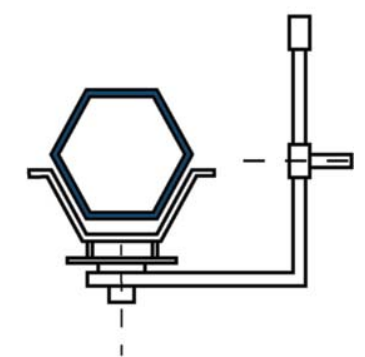

De-molding

Figure 1. Rotational molding process

\section{Process control for rotational molding}

\subsection{The RM cycle}

During RM, the charged mold is heated at a constant temperature. Despite this, the process of heating and cooling cannot be considered isothermal since thermal losses by the oven and in-homogenous heating of the polymer occur frequently [8]. Thermograms recorded by a thermocouple in the mold cavity (Figure 2) typically show va kink in the heating curve (point 1); which for semi crystalline polymer powders, corresponds to the beginning of melting. From this point the temperature curve is a semi plateau; which continues to rise gradually until a point (2) where it is accelerated. At this stage the powder bed is depleted; however, the melt is in-homogenous with numerous air bubbles. Point (2) corresponds with the beginning of the densification period which ends when a peak internal air temperature (PIAT) is reached (point 3). Once PIAT is achieved, heating of the mold is stopped and cooling begins. At the point (3), the curve possesses a characteristic rounding off that is caused by the polymer layers closest to the mold wall cooling down faster than inner layers. From point (3) the curve inverts and cooling proceeds gradually until point (4) when crystallization begins. A semi plateau is observed here as well and continues until point (5), which corresponds to the end of crystallization and

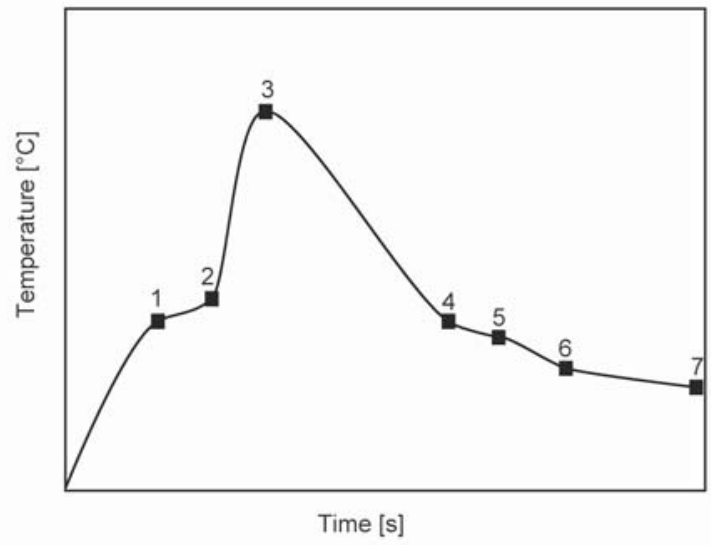

Figure 2. Thermogram for the rotational molding cycle of a semi-crystalline polymer

solidification. Cooling continues and a slight change in slope is observed at the point (6); which is caused by separation of plastic from the mold surface and the subsequent formation of an insulating layer of air between the them [1]. De-molding temperatures are achieved at the point (7) and the finished product can be removed from the mold. Depending on the wall thickness of the molding, RM cycles can require between 40 to 80 minutes for completion [9].

\subsection{Models for heat transfer in RM}

All current research more or less agrees with a set of governing equations for heat transfer in RM. The bone of contention lies with the representation of $\Delta H$ during polymer melting and solidification (Equation (1). Two dominant thermal models in existence that can describe these phenomena are: the front tracking and fixed domain models [10]:

$\frac{\mathrm{d}}{\mathrm{d} t}\left(\rho_{\mathrm{p}} C_{\mathrm{p}} T\right)+\Delta H=\frac{\partial}{\partial z}\left(k_{\mathrm{p}} \frac{\partial T}{\partial z}\right)$

where $\Delta H$ is the heat required for phase change of the polymer, $\rho_{\mathrm{p}}$ and $C_{\mathrm{p}}$ are the polymer density and heat capacity respectively, $k_{\mathrm{p}}$ is the conductivity of the polymer layer in either solid $\left(k_{\mathrm{p}}=k_{\mathrm{sp}}\right)$ or liquid $\left(k_{\mathrm{p}}=k_{\mathrm{lp}}\right)$ states and $z$ is the distance from the outer mold surface.

The thermal parameters $\rho_{\mathrm{p}}$ and $C_{\mathrm{p}}$ and $k_{\mathrm{p}}$ are temperature dependent. Generally, the complications encountered when modelling heat transfer in RM concern the number of initial and boundary conditions that have to be accounted for. This is especially true when the contact between the mold surface and the polymer powder must accurately depict real life molding conditions. 


\subsubsection{Front tracking model}

This is a dual-phase kinetic model in which the polymer melt and powder layers (or polymer melt and solid layers during cooling) are separated by an interface. The powder layer melts when the temperature at the interface $\left(T_{\mathrm{i}}\right)$ reaches polymer melting temperature $\left(T_{\mathrm{m}}\right)$. As melting proceeds the interface moves the from the mold surface through subsequent powder layers until all of the powder is melted [11]. During cooling a similar process occurs at the interface as $T_{\mathrm{i}}$ approaches the crystallization temperature $\left(T_{\mathrm{c}}\right)$ at each consecutive interface position.

Early proponents of this method include Rao and Throne [12]; whose work considered the complex tumbling of powder particles within the mold in its description of heat transfer. The model showed poor correlation with experimental results. Improvements by Throne [13] suggested that the powder mass be considered static in the mold (static bed), ignoring the complex powder kinetics. The simplified model had much better agreement with experimental results. This early success resulted in a slew of works that applied the front tracking model [11, 14-19]. However, the front tracking model is complicated and its implementation especially tedious due to the additional boundary conditions that must be satisfied at the melt/powder interface; and the necessity to track the position of this interface as it moves from the mold surface through the powder thickness [11, 17]. Another difficulty is the poor representation of the pseudo plateaus of melting and crystallization. Because $T_{\mathrm{i}}$ is taken to be constant (i.e. equal to either $T_{\mathrm{m}}$ or $T_{\mathrm{c}}$ ), solving of the thermal balance equation generates a constant temperature plateau at points associated with phase change [12-16]. Employing a discreet number of $T_{\mathrm{m}}$ results in marginal improvements $[18,19]$.

Gogos and coworkers $[11,17]$ assumed a well-mixed powder as a result of the tumbling action during mold rotation. The temperature of the powder was uniform across its volume and increased evenly with time. Numerical results more closely resembled those obtained empirically; however, due to the well mixed assumption, internal air temperatures (IAT) increased much slower than expected.

\subsubsection{Fixed domain model}

Proponents of the fixed domain point to the shortcomings of the front tracking model as the main merits of their method. Indeed, this model does not require the application of a melt powder interface; and by extension the boundary conditions that are required in order to define it [8]. The models currently being investigated for RM can be divided into temperature based [10, 20, 21], source based [22] and enthalpybased [23-26]. In this instance as well the main difference between them is the manner in which $\Delta H$ is represented.

Lim and Ianakiev $[10,20]$ presented the energy equation of the bulk air inside the mold as a lumped parameter system that they combined with a coincident node technique and Galerkin finite element method (FEM). The model predicted the stratified deposition of polymer melt onto the mold wall, and although successful in capturing polymer phase change, it predicted an earlier shorter and less pronounced pseudo plateau of melting when compared with experimental results. The numerical melting phase proceeded faster than expected, which could not be accounted for by the layer-by-layer deposition.

Banerjee et al. [22] incorporated into Equation (1) the latent heats of melting and crystallization as a sink/ source term respectively (Equation (2)):

$\Delta H=\rho_{\mathrm{p}} H_{\mathrm{m}} \frac{\partial \lambda}{\partial t}$

where $\rho_{\mathrm{p}} H_{\mathrm{m}}$ is the latent heat per unit volume, and $\partial \lambda / \partial t$ is the melting rate.

As a result of the imperfect contact between itself and the mold, the tumbling powder was heated by convection and heat transfer in the powder mass occurred by conduction only. A finite difference scheme discretized the governing equations and boundary conditions. The model predicted the layer-by-layer deposition of the melt in good agreement with experiments.

For the enthalpy based models two approaches are encountered in literature Sarrabi et al. [8] and Tcharkhtchi et al. [27] presented a non-empirical solution for Equation (1) derived from the Law of global enthalpy change with temperature. A finite differences scheme discretized the core equations of the model using a first order implicit Euler algorithm. The model represented the pseudo plateau of melting well; that of crystallization was, however, unsatisfactory. The authors attributed this difference between numerical and experimental results to crystallization kinetics; which their model did not account for.

The second approach encountered [23-26] is the expression of the total phase transition enthalpy as 
function of the degree of melting and crystallization; following which Equation (1) takes the form shown in Equation (3):

$\frac{\mathrm{d}}{\mathrm{d} t}\left(\rho_{\mathrm{p}} C_{\mathrm{p}} T\right)+\rho_{\mathrm{p}} H_{\mathrm{m}} \frac{\mathrm{d} X_{\mathrm{m}}}{\mathrm{d} t}-\rho_{\mathrm{p}} H_{\mathrm{c}} \frac{\mathrm{d} X_{\mathrm{c}}}{\mathrm{d} t}=\frac{\partial}{\partial z}\left(k_{\mathrm{p}} \frac{\partial T}{\partial z}\right)$

where $X_{\mathrm{m}}$ is the degree of melting and $X_{\mathrm{c}}$ is the degree crystallization.

Greco et al. [23], through differential scanning calorimetry (DSC), obtained the melting temperature distributions $\left(\mathrm{d} X_{\mathrm{m}} / \mathrm{d} T\right)$. An Avrami-derived equation accounted for the crystallization kinetics $\left(\mathrm{d} X_{\mathrm{c}} / \mathrm{d} T\right)$ of the melt and a Crank-Nicholson method discretized the governing equations. Results for both melting and crystallization phases were satisfactory.

\subsection{Process monitoring and control systems}

A majority of the systems designed to monitor and control RM focus on the thermal aspect of the process. Among the earliest commercial systems includes RotoSim ${ }^{\mathrm{TM}}$, a program developed for the analysis of powder kinematics in a 3-D space [18, 28]; following which mold local temperature profiles could be developed and cycle times approximated. Although it is a widely used RM simulator, it has faced criticism for its long computational periods [22] and numerical inaccuracies [8].

Of particular significance was the introduction of Rotolog ${ }^{\text {TM }}$ in the early 1990's [29]. The system consists of thermocouples and an insulated radio transmitter that is used to measure and relay in-mold air temperature profiles. Earlier versions of the system fixed onto the machine arm where the transmitter was in constant risk of overheating. Recent iterations, however, make use of slip rings mounted permanently in the hollow machine arm; which allows the transmitter to be located further away from the oven [30]. Automatic control of the RM cycle is made possible through the integration into this system, of an adaptive computer network. Data received from the transmitter is analyzed by a computer program which sends a signal to the machine to take the necessary regulatory action on the heating or cooling rates [31]. Other commercial mold temperature monitoring systems that work on a similar principle include: EZ Logger from Paladin, TempLogger, RotoPaq and K-Control from $493 \mathrm{~K}$.

InfraRed Thermometry ${ }^{\mathrm{TM}}[32,33]$ is yet another system that is used to automatically regulate the RM process. As the name suggests, it makes use of infrared thermometers, in the oven and cooling chamber, to collect data on the condition of the mold. This data is processed and the mold temperature profile is used to control the heating and cooling rates.

Two other process control systems that deserve mention include: K-Paq ${ }^{\mathrm{TM}}$; a portable device that measures internal mold pressures and temperatures [30] and RotocoolerTM ; a mold cooling device that makes use of both internal and external water sprays $[6,34,35]$.

\section{Surface finish}

Surface quality in RM depends on a number of factors that includes: The material system, particle shape and size, temperature and mold surface finish. Good quality surfaces are likely the most difficult feature to achieve through RM. This is due to in part to the low thermal stability possessed by plastics, which makes them vulnerable to degradation and deformation during processing. This is exacerbated by the zero shear nature of the process; which means that one of the few means to achieve high quality surfaces is the accurate control of air temperatures within the mold. If PIATs are too low imperfections such as: poor particle cohesion and bubbles or surface porosity, arise. On the other hand, degradation of the polymer occurs when PIATs are excessively high [36]. This need for accurate temperature control extends to the cooling stage of the process as well; where improper regulation of cooling rates results in the warping of surfaces [37].

\subsection{Bubble formation and the effect of powder shape and size}

Surface porosity and bubbles within the part result in unfavorable aesthetics, while leading to deterioration in mechanical properties of the plastic moldings. Early attempts at describing the mechanism of bubble formation in polymers were adapted from metal sintering. During sintering, polymer particles that are exposed to elevated temperatures fuse together at their contact points (Figure 3). The total surface area of the particles reduces rapidly, predominantly as a result of surface tension. During this period air can still migrate through the free passages between particles. However, as time progresses, the particles melt completely and form a three dimensional network around air pockets still remaining between the particles resulting in bubbles [38]. 


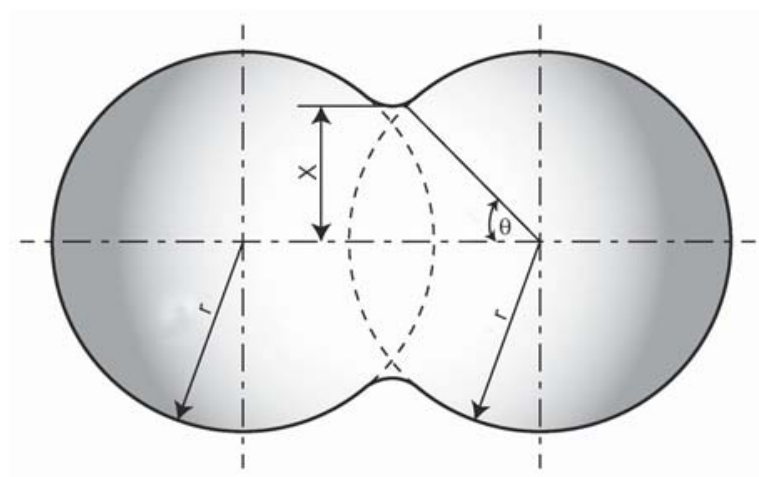

Figure 3. Sintering process for two equally sized particles

Frenkel [39] was the first to derive a numerical solution for the Newtonian viscous sintering of two spherical particles under the action of surface tension (Equation (4)). Subsequently, a correction was proposed by Eshelby [40] that solved the continuity error and took account of the initial particle radius (Equation (5)). This model was limited to the initial stages of sintering when particle radii were more or less constant:

$\frac{x^{2}}{r}=\frac{3}{2}\left(\frac{\gamma}{\mu}\right)^{\mathrm{t}}$

where $x$ is the neck radius, $r$ is the sphere radius, $\gamma$ is the surface tension, $\mu$ is viscosity and $t$ is time.

$\frac{x}{r}=\left(\frac{t \gamma}{\mu r_{0}}\right)^{\frac{1}{2}}$

where $r_{0}$ is the initial particle radius.

Variations of the Frenkel-Eshelby model have since been used by a number of authors to describe the sintering of various materials including glass [41-43] and polymers [44-46]. However, this model only takes into account the effects of viscosity and surface tension and is unable to adequately describe the sintering process for some polymers. Pokluda et al. [45] for instance, developed a model that predicted the entire sintering process. They observed that the model predicted a much faster sintering when compared with experiments carried by out Bellehumeur et al. [47] on propylene ethylene copolymers. They attributed this to the viscoelastic effects of the polymers which the model did not account for. A similar observation had been made in an earlier work by Lontz [48].

In an attempt to explain this phenomenon Bellehumeur et al. [49] carried out rheometer tests and found that stress relaxation after steady shear varied significantly between materials. In light of these results, they proposed a viscoelastic model derived from the convected Maxwell model (Equations (6)(8). The predictions obtained from this model closely matched the results obtained experimentally. The model also correctly predicted a slower sintering rate with increasing elasticity:

$$
\begin{aligned}
& 8\left(r \lambda K_{1} \theta^{\prime}\right)^{2}+\left(2 r \lambda K_{1}+\frac{\mu r_{0}}{\gamma} \frac{K_{1}^{2}}{K_{2}}\right) \theta^{\prime}-1=0 \\
& K_{1}=\frac{\sin \theta}{(1+\cos \theta)(2-\cos \theta)} \\
& K_{2}=\frac{2^{-\frac{5}{3}} \cos \theta \sin \theta}{(1+\cos \theta)^{\frac{4}{3}}(2-\cos \theta)^{\frac{5}{3}}}
\end{aligned}
$$

where $\lambda$ is the relaxation time, and $\sin \theta=x / r$.

More recently, Hamidi et al. [50] made experimental observations that the rate of sintering reduced with the introduction of a third powder particle. They modified Bellehumeur's model by introducing a geometric parameter they referred to as the 'Farz Factor'; which adjusted the surface tension term and allowed them to predict the effect of surrounding particles. Model and experimental work correlated fairly well.

Powder characteristics have a significant effect on the flow characteristics, packing density and heat transfer; which consequently, affect the sintering of polymer within the mold $[1,12,49,51-53]$. In RM powder flow depends primarily on mold surface finish particle shape and particle size distribution. Depending on these factors, a number of flow regimes can be observed at speeds of between 4-20 rpm which are typical of the RM cycle (Figure 4) [1, 52].

Slip flow arises mainly as a result of low frictional forces between a highly polished mold surface and the powder particles. When the mold is rotated, the powder bed is raised up to an angle beyond which the frictional force is not sufficient to support its mass. At this point the entire bed slides down along the mold surface. Similarly, powder shape plays a significant role and slip flow is observed for diskshaped particles that possess very high packing densities. This flow mechanism is characterized by increased porosity, poor powder mixing and poor heat transfer. Apart from selecting the suitably shaped powders, Crawford and Throne [1] also recommend that mold surfaces should be finished by sand blasting using 100-200 mesh particles.

Steady state flow and avalanching are more common in rotational molding than the previously mentioned 


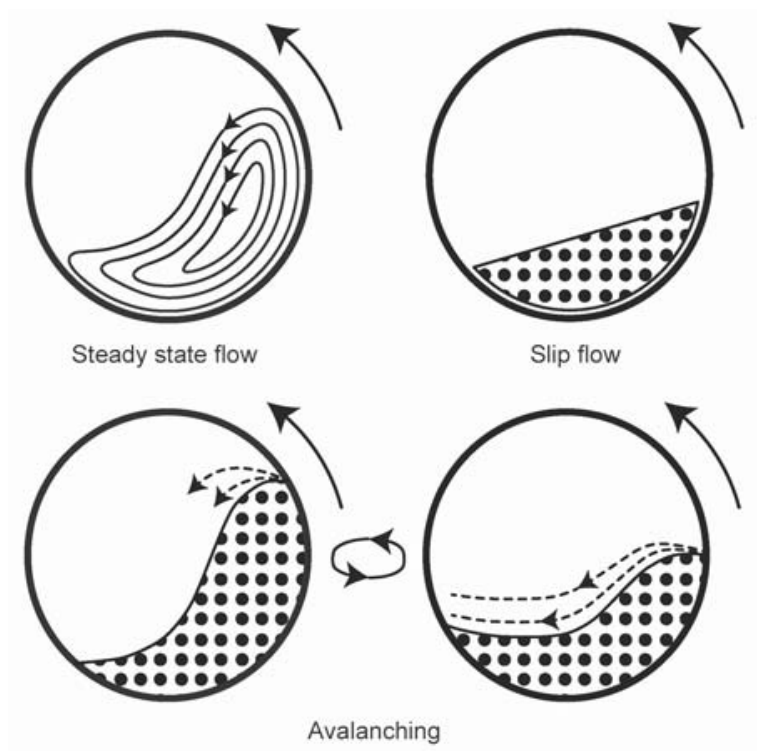

Figure 4. Powder flow during rotational molding

slip flow. During steady state flow, the powder particles in contact with the mold surface are lifted by the rotating mold. Once the angle of repose is exceeded, these powder particles break off from the mold surface and tumble across the surface of the powder bed. For avalanching, on the other hand, the entire bed is raised by the rotating mold surface until the dynamic angle of repose is exceeded. Once this occurs, the top portion of the bed breaks off from the mold and tumbles across the surface of the bed. Steady state flow is usually observed for spherical particles, while the avalanching occurs when squared egg particles are used [1]. Disk-shaped particles can also cause both types of flow when surface friction allows it. Steady state flow and avalanching are both characterized by good heat transfer, mixing and powder flow; however, these characteristics are generally better for the former.

From the discussions above it can be seen that regularly shaped powders are preferred in RM. Although irregular shapes provide a larger surface area for heat transfer, they should be avoided since they negatively affect bulk density and lead to increased porosity; the net result of which is lower thermal conductivity [53]. Spherically shaped particles also possess low packing densities and produce moldings with increased surface porosity. Ideally, squared egg shaped powder particles should be used where possible, as they result in the best overall surface quality $[1,53]$. The role of powder size and powder size distribution in bubble formation should also be taken into consideration. The application of particles larger than recommended is usually accompanied by a number of concerns. Firstly, larger sized particles require a longer duration of time for heat to penetrate to their centers and sintering occurs at a slower rate than for smaller particles [51, 53]. Secondly, larger sized particles also result in a larger void fraction at the end of sintering, because of the increased inter-particle space [54]. However, it is difficult to obtain powders made up entirely of fine particles due to energy and time constraints [12]. In RM a balance is established between these factors by specifying a suitable powder size distribution. Typical RM powder sizes vary in size between -35 mesh to 200 mesh [1].

Spence and Crawford [38] observed that the maximum pore size in PE moldings reduced drastically when $40 \%$ of fine particles were applied in the polymer powder. Further increases did not significantly improve surface quality. Also, surface porosity reduced with increasing fine particle content in the powder. They theorized that this improvement in surface porosity was as a result of the sieving action in RM which caused the finer particles to be deposited onto the mold surface first. Olinek et al. [52] confirmed this observation by uni-axially rotating a mixture of coarse and fine PE powder in a cylindrical mold that was provided with windows on the side walls. Experiments showed that at low heating rates the fine particles tended to segregate themselves at the surface of the heated mold.

\subsection{Mechanism of bubble removal}

For the specific case of RM, Rao and Throne [12] and Progelhof et al. [55] incorrectly theorized that bubbles either slowly migrated to the free surface or remained encapsulated in the polymer after quenching. Kelly [56], on the other hand, observed that the bubbles formed during sintering remained stationary due to high melt viscosity. Instead, oxygen (more soluble than nitrogen in $\mathrm{PE}$ ) dissolved into the polymer melt as temperature and hence pressure within the bubble increased. Surface tension forces caused a reduction in bubble diameter, which in turn increased pressure within the bubble; and nitrogen also dissolved into the melt. The process repeated itself until the entire bubble diffused and at very long cycle times the voids disappeared. This bubble collapse mechanism is now widely accepted in RM.

Crawford and Scott [57] discerned two separate and distinct bulk movements: progression of the molten polymer across the powder mass to the free surface; and the collapse of the powder particles into the melt 

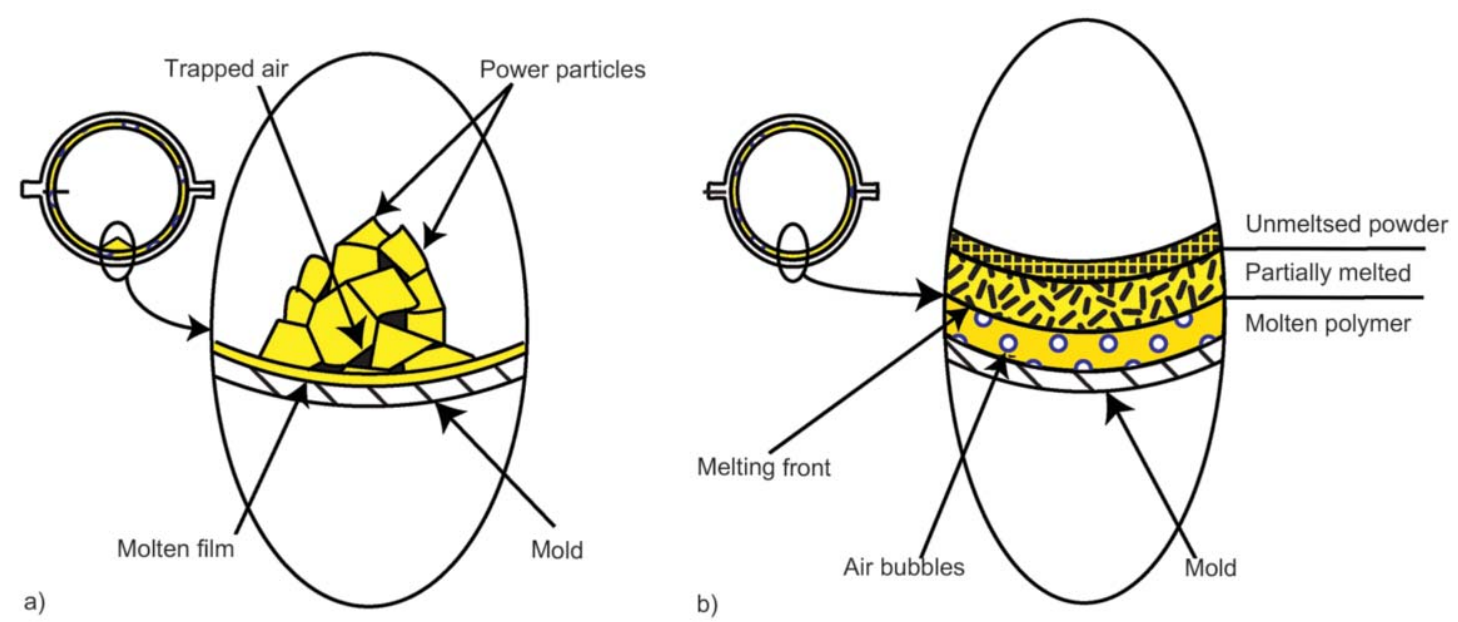

Figure 5. Entrapment and retention of voids during a) sintering, b) densification

resulting in bubbles (Figure 5). The dissolution rate of the bubbles depended on their initial sizes; which, in turn, depended on powder particle size. Larger sized particles gave rise to larger sized bubbles which diffused considerably slower. The authors developed the empirical model for the air bubble removal rates as shown in Equation (9):

$\left(\frac{\varphi}{\varphi_{0}}\right)^{2}=K_{3}-K_{2} t$

where $\varphi$ is the diameter of the bubble, $\varphi_{0}$ is the original diameter of the bubble, $t$ is time and $K_{2}$ and $K_{3}$ are empirical constants.

Crawford and $\mathrm{Xu}$ [58] later proposed an improvement to this model and from their work observed that a more accurate relationship could be given by the Equation (10):

$\left(\frac{\varphi}{\varphi_{0}}\right)^{2}=K_{5}-K_{2} t+K_{6} t^{2}$

where $K_{5}$ and $K_{6}$ are constants

In RM, bubble and pinhole removal is a time consuming process. Standard industry practice involves holding the polymer at elevated temperatures, for a period that corresponds to $40 \%$ of the RM cycle, in an attempt to remove bubbles [59]. Because of this a substantial amount of effort has gone into research on the bubble removal process and the variables that affect it.

Spence and Crawford [38] observed increased bubble and pinhole prevalence in polyethylene (PE) with: the addition of carbon black; reduced MFI; lower peak temperatures; reduced cycle time; reduced fraction of fine particles; and the application of mold release agents. The application of release agents reduced the surface tension of the mold, while addition of carbon black, reduced MFI and lower temperatures increased melt viscosity; which, according to the authors, restricted the passage of air molecules through the polymer melt,. An increase in PIAT of up to $250^{\circ} \mathrm{C}$ proved most effective for bubble removal because it:

(i) Ensured that the polymer remained in its molten state for a longer duration, which allowed greater bubble diffusion;

(ii) Caused an increase in pressure within the bubbles and a corresponding reduction in their radii due to the effect of surface tension forces;

(ii) Depleted the residual oxygen within the bubbles by direct oxidation reactions with the surrounding polymer.

Although increased PIAT effectively eliminated bubbles, it also resulted in reduced production efficiency and loss in mechanical properties for the molded parts. Spence and Crawford [60] presented pressurization as a means of increasing the bubble dissolution rate. The application of pressure after polymer melting resulted in a faster the rate of bubble dissolution and reduced surface porosity. Results for different values of IAT and a pressure of 0.5 bar showed that the application of pressure was more effective at higher melt temperatures. The authors, once again, attributed the increased rate of bubble diffusion to reduced viscosity at higher melt temperatures. An evaluation of the mechanical properties of the molding samples showed improved low temperature $\left(-20^{\circ} \mathrm{C}\right)$ impact toughness and tensile strength. Bending properties were, however, not affected.

Kontopoulou and Vlachopoulos [54], based on the work of Spence and Crawford, developed a 
semi-empirical model that applied diffusion, surface tension and viscosity effects in order to describe the dissolution of a single spherical gas bubble in a polymer melt. A finite difference method and a forward Eulerian scheme discretized the governing equations. Results showed that the bubble dissolution rate depended mainly on the initial size of the bubbles and air concentration in the melt. Melt viscosity, unlike in previous observations $[38,60]$, influenced very little when within typical limits imposed on RM polymers. An evaluation of the force balance at bubble-polymer interface (Equation (11)) showed that at the initial stage of bubble dissolution, the surface tension term was 150 times larger than the viscosity dependent normal stress. With increased time the bubble grew smaller and normal stress at the gas/polymer interface increased significantly. The surface tension term became only three to four times greater; only at this point did normal stress begin influence dissolution rates:

$$
P(R)=\tau_{\mathrm{rr}}(R)+P_{\mathrm{g}}-\frac{2 \gamma}{R}
$$

where $P(R)$ and $\tau_{\mathrm{rr}}(R)$ are the ambient pressure and normal stress at the gas/polymer interface respectively; $P_{\mathrm{g}}$ is average gas pressure within the bubble; and $\gamma$ is surface tension.

The authors attributed the increased bubble dissolution rates in pressurized molds to an increase in gas pressure within the bubble with increased ambient pressure. Surface tension forces caused an immediate reduction in bubble diameter. Also, with increased pressure, air concentration at the gas/polymer interface increased, while the concentration within the melt remained unchanged. The steep concentration gradient significantly increased air diffusion rates across the interface. Comparisons between the results obtained by simulation closely matched those reported by Spence [61].

Gogos [59] formulated a series of closed form equations, which described the effects of surface tension and pressurization on the dissolution rates of a single nitrogen bubble in PE; at varied degrees of polymer melt saturation. At saturation levels close to unity, the model showed that surface tension was dominant in the concentration gradient that drives dissolution. Pressurization resulted in reduced bubble life-times. The author confirmed observations made by Kontopoulou and Vlachopoulos; and attributed the increased dissolution rates to the steep concentration gradient at the gas/polymer interface produced by increased pressure. In under-saturated melts, the surface tension term was negligible and the concentration gradient itself dominated the driving force for bubble dissolution. Bubbles in the under-saturated melt diffused much faster than in both pressurized conditions and at saturation levels close to unity.

\subsection{Polymer degradation during processing}

Polymer degradation leads to deterioration in surface quality of parts, e.g. discoloration and loss of glossiness or texture, accompanied by a loss in mechanical properties [36, 62]. In RM, optimum PIAT occurs just before the onset of polymer degradation [62-64]. At this temperature, melt viscosity is still relatively high but processing of the polymer is more convenient [65]. However, due to the low thermal stability of polymers and the high processing temperatures inherent to the process, its materials are prone to thermal degradation; mainly through oxidative processes $[8,62]$. The degradation of most RM polymer systems begins when a chain loses its hydrogen atom due to energy input from heat. This results in the formation of a hydrogen atom with an unpaired electron and a very unstable free radical (Equation (12)). The propagation of oxidation occurs when the free radical formed in Equation (12) reacts with oxygen to form a peroxyde radical, which liberates hydrogen from the polymer (Equations (13) and (14)). This results in the formation of an unstable polymer hydroperoxide and a new free radical:

$$
\begin{aligned}
& \mathrm{PH} \stackrel{\text { heat }}{\longrightarrow} \mathrm{P}^{*}+\mathrm{H}^{\cdot} \\
& \mathrm{P}^{+}+\mathrm{O}_{2} \stackrel{\text { heat }}{\longrightarrow} \mathrm{POO} \\
& \mathrm{POO}+\mathrm{PH} \stackrel{\text { heat }}{\longrightarrow} \mathrm{POOH}+\mathrm{P}^{\circ}
\end{aligned}
$$

where $\mathrm{PH}$ is a polymer molecule, $\mathrm{P}$. is a free radical, $\mathrm{O}_{2}$ is oxygen, $\mathrm{POO}$ is a peroxyde radical and $\mathrm{POOH}$ is hydroperoxide.

The hydroperoxides formed are unstable and can decompose to form other volatile products (Equations (15)-(17)):

$$
\begin{aligned}
& \mathrm{POOH} \rightarrow \mathrm{PO}^{*}+\mathrm{OH}^{\cdot} \\
& \mathrm{PO}^{*}+\mathrm{PH} \rightarrow \mathrm{POH}+\mathrm{P}^{\circ} \\
& \mathrm{OH}^{*}+\mathrm{PH} \rightarrow \mathrm{H}_{2} \mathrm{O}+\mathrm{P}^{.}
\end{aligned}
$$

In the absence of antioxidants, the process repeats itself until non radical products are formed (Equations (18)-(20)) $[8,65,66]$ : 
$\mathrm{P}^{\cdot}+\mathrm{P}^{\cdot} \rightarrow \mathrm{IP}$

$\mathrm{P}^{*}+\mathrm{POO}^{\cdot} \rightarrow \mathrm{IP}$

$\mathrm{POO}^{*}+\mathrm{POO}^{*} \rightarrow \mathrm{IP}+\mathrm{O}_{2}$

where IP are inactive products.

The above mechanism was first presented for polyolefins [67], which make up a majority of the polymers used in RM (PE and polypropylene). It has also been used to describe the degradation of polyamides [68] and aromatic esters (polyethylene terephthalate and polybutylene terephthalate) $[69,70]$ amongst others. Anti-oxidants are necessary to enable the processing of these polymers as well as to ensure their longevity in service. These take the form of hindered phenols and phosphites [36]. Hindered phenols are radical chain terminators that contain a number of labile hydrogen atoms which they readily dissociate to inhibit free radical formation and more rapidly stabilize the peroxyl radicals already formed. Phosphites on the other hand are preventive antioxidants that act to hinder the initiation of the oxidation process by preventing the decomposition of unstable polymer hydroperoxides.

The thermal degradation mechanism for polyvinyl chloride (PVC) is slightly different from the one presented for polyolefins. The process is caused mainly by structural irregularities in the polymer inherited from its polymerization and is made up of two main reactions. During the initial stage (primary reaction), high processing temperatures cause free hydrogen chloride $(\mathrm{HCl})$ to be evolved by eliminating chlorine from the polymer backbone. This is accompanied by discoloration and the formation of conjugated polyene sequences within polymer chains. In the secondary reaction, polyene reacts with oxygen resulting in peroxyde radicals and hydroperoxides [71]. Decomposition of the hydroperoxides then proceeds according to the scheme presented by Bolland [67]. Due to the difference in reaction mechanisms, a different set of degradation inhibitors is required for the melt processing of PVC. Heat stabilizers prevent thermo-oxidative degradation in two ways:

(i) Primary stabilizers, with strong Lewis acid character, react with intermediates in the degradation chain (allylic chlorides) and prevent the formation of polyenes longer than four to five double bonds [71].

(ii) Secondary stabilizers scavenge the evolved $\mathrm{HCl}$ and prevent its auto-catalytic effects on chain initiation that can start other dehydrochlorination events [72].

Alkyltin stabilizers are an important group of primary stabilizers. Although they can react with $\mathrm{HCl}$ to form tin chlorides, their main contribution to dehydrochlorination is to react with allylic chlorides. For example, alkyltin thioglycolates can exchange the thioglycolate group for $\mathrm{Cl}$ atoms during reaction with allylic chlorides [71]. $\beta$-Diketones, epoxidized Fatty Acid Esters and some metal carboxylates also find application as primary stabilizers. Metal carboxylates based on zinc $(\mathrm{Zn})$ and cadmium $(\mathrm{Cd})$ react in a similar manner to alkyltin stabilizers; however, those base on calcium $(\mathrm{Ca})$, potassium $(\mathrm{K})$ and barium $(\mathrm{Ba})$ only scavenge $\mathrm{HCl}$, and are considered secondary stabilizers. Other secondary stabilizers include phosphites and hydrotalcites.

Combinations of both primary and secondary stabilizers, that possess synergistic effects, have shown to provide the best improvements in high temperature performance. Indeed, when Kovařík et al. [72] investigated the performance of stabilizers based on $\mathrm{CaO}$, zinc stearate ( $\mathrm{ZnSt})$, and the Sterically Hindered Phenolic Antioxidant Irganox 1010, they observed that the polymer remained thermally stable for more than 60 minutes at $180^{\circ} \mathrm{C}$. Unfortunately, the sheer volume of work related to polymer thermooxidative degradation cannot allow a full assessment of all its aspects in this review. It is recommended that further information on oxidation and the stabilizing effects of antioxidants be sought from the comprehensive reviews given in references [62, 71-76].

Predicting the onset of degradation during RM is a topic of great interest for researchers. This is motivated by the fact that molders for a long time determined optimum PIAT largely by trial and error; a method that is as expensive as it is inefficient. The rate constants of elementary reaction during thermal oxidative degradation adhere to the zero order Arrhenius equation. Models derived from it analyzed and fairly accurately predicted the thermal stability of various polymers including; PVC [77], polylactic acid (PLLA) [78] and polypropylene (PP) $[8,66]$ in RM conditions.

Of particular significance is the work carried out by Cramez et al. [36], who predicted the onset of degradation by determining the time required to completely exhaust antioxidant in a PE; also referred to as oxidation induction time (OIT). Since temperature 
Table 1. Theoretical and experimental degradation temperatures for PE [45]

\begin{tabular}{|l|l|c|c|c|c|}
\hline \multirow{2}{*}{ Material } & \multicolumn{1}{|c|}{ Mold type } & \multirow{2}{*}{$\begin{array}{c}\text { Oven temperature } \\
{\left[{ }^{\circ} \mathbf{C}\right]}\end{array}$} & \multirow{2}{*}{$\begin{array}{c}\text { Heating rate } \\
{\left[{ }^{\circ} \mathbf{C} / \mathbf{m i n}\right]}\end{array}$} & \multicolumn{2}{c|}{$\begin{array}{c}\text { Temperature of degradation } \\
{\left[{ }^{\circ} \mathbf{C}\right]}\end{array}$} \\
\cline { 5 - 6 } & & & & Theoretical & Experimental \\
\hline Sclair 8504 & Aluminum & 300 & 9 & 221.0 & $213-225$ \\
\hline Sclair 8504 & Stainless steel & 300 & 10 & 222.0 & $215-225$ \\
\hline Sclair 8504 & Mild steel & 300 & 13 & 227.0 & $224-240$ \\
\hline ME 8152 & Mild steel & 270 & 9 & 233.4 & $233-239$ \\
\hline ME 8152 & Mild steel & 330 & 16 & 245.1 & $241-247$ \\
\hline
\end{tabular}

during RM is not constant, they determined that for non-isothermal heating the concentration of antioxidant at any point in time could be given by Equation (21):

$$
-\frac{\mathrm{d} c}{\mathrm{~d} t}=k_{0} \cdot \exp \left(-\frac{E}{R \cdot\left(T_{0}+r \cdot t\right)}\right)
$$

where $c$ is the antioxidant concentration at time $t, k_{0}$ is the kinetic rate constant, $T_{0}$ is the minimum temperature for antioxidant consumption, $E$ is the activation energy, $R$ is the gas constant and $r$ is the constant heating rate.

The OIT for a PE powder obtained at different temperatures by DSC generated the $\ln \left(t_{\mathrm{i}}\right)$ vs $1 / T$ curves. Form these curves the authors determined the values of $E$ and $k_{0}$ which they substituted into Equation (21); alongside the heating rates $(r)$ from the RM trials. Theoretically obtained values for $T_{0}$ showed good agreement with experimental results (Table 1).

\subsection{Dimensional stability}

Warping is caused by an uneven stress build up across the thickness of a cooling polymer which results in a bending moment. In RM the mold is cooled from the outside only. The layer in contact with the mold surface cools and contracts unhindered. Once the outer layer solidifies, subsequent inner layers also start to cool; however, in this instance complete contraction is prevented by the outer layer. Thus, a stress profile develops and with it a bending moment in an attempt to relieve these stresses. Previous research identified the cooling rate as the largest contributor to this uneven stress build up $[37,79,80]$.

Bawiskar and White [79] studied the warpage of different polymers subjected to various cooling conditions and concluded that; increased cooling rates corresponded with an increase in warpage and shrinkage. Liu and Ho [37] confirmed these observations and investigated the effects of other processing parameters. In their experiments, part warpage increased with: increased part thickness, increased oven temperature, mold materials of high thermal diffusivity and the addition of pigments. Their observations on part thickness contradicted Pop-Iliev et al. [80] who experienced the exact opposite in their experiments. Glomsaker et al. [81] attributed these conflicting results to mold release agents, without which their results were consistent with Liu and Ho's [37]; while the their application gave results similar to Pop-Iliev et al. [80] Both increased oven temperatures and mold materials with higher thermal diffusivity, increased the temperature differences between the inner and outer surfaces of the mold. Liu and Ho [37] attributed the observed effect of pigments to reduced mechanical properties of the samples. However, Nagy and White [82] previously obtained similar results for PE but observed that no correlation between warpage and pigments could be established since the experiments were designed to achieve measurable deformation; also, they experienced only reduced impact energy in the pigmented samples.

The temperature gradient in RM causes variations in the morphological characteristics of semi-crystalline polymers [76]. The surfaces in contact with the mold wall cool and solidify rapidly resulting in a large number of fine spherulitic structures. The free surface, however, cools down slower than the outer surface; which allows the nucleation of only a small number of spherulites whose unimpeded growth results in larger and coarser spherulitic structures and higher crystallization. These morphological variations become more pronounced with increasing cooling rates [25]. The crystallinity gradient, in a manner similar to the temperature gradient, acts to increase the residual stresses within the parts and consequently warpage. Researchers have developed models examining the effect of crystallization kinetics on warpage [24, 26, $81,83]$. The models used in a majority of these works are based on the Kolmogoroff-Avrami-Evans statistical theory (Equation (22)) [84-86]: 
$X_{\mathrm{c}}=1-\exp \left(-k_{\mathrm{c}} t^{\mathrm{n}}\right)$

where $k_{\mathrm{c}}$ is a temperature-dependent kinetic parameter, and $n$ is the Avrami index.

Glomsaker et al. [81] placed linear low density PE (LLDPE) samples onto a substrate and heated them inside a thermally insulated box until they melted. The authors assumed the material to be purely elastic and cooled it from one side in a fashion similar to $\mathrm{RM}$. The viscoelastic properties of the material were contained in a critical value of accumulated elastic energy at which the plastic samples overcame their adhesion to the substrate. At separation the elastic energy dissipated and final residual stresses could be determined. Results showed that at low cooling rates typical for air cooled molds, the temperature gradient was minimal and warpage occurred mainly due to the crystallinity gradient.

$\mathrm{Xu}$ and Bellehumeur [26] neglected the effects of viscoelasticity and adhesion to the mold. Their experimental data and thermo-mechanical model, however, more closely represented actual RM conditions. The authors observed that higher crystallinity gave rise to higher part stiffness. This, unfortunately, was accompanied by higher residual stress and bending moment values which as expected led to greater warpage. Both $\mathrm{Xu}$ and Glomsaker did not take into consideration the change in material elastic modulus due to the effects of temperature at different stages of the RM cycle. Both works assumed that the modulus is entirely dependent on the level of crystallinity within the part.

\section{Cycle times}

In comparison with other polymer processing techniques RM's productivity is negatively affected by its relatively longer molding cycles. The rate at which in mold temperatures increase depends entirely on the temperature difference between the mold and the oven. Therefore, the simplest way to reduce cycle times would be to increase this temperature difference by increasing oven temperature during heating. However, as shown in section 3, this approach is problematic. Alternatively, increasing the oven's air flow rate shortens cycle times and avoids degradation; but negatively affects efficiency. The modification of the molds and machines has the potential to reduce cycle times without the previously mentioned drawbacks. Previous work showed that improvements in the design of molds, heating and cooling equipment can significantly reduce the cycle times.

\subsection{Direct mold heating}

Monzón et al. [87] proposed a novel mold design constructed from an electro-formed metallic shell, which a thermal fluid heated and cooled directly. While channels cast integrally with or welded onto the mold supply the heating oil in conventional designs, this design used manifolds with inlet and outlet pipes to supply to and remove externally heated fluid from an open channel. Using computational fluid dynamics (CFD) the researchers analyzed the performance of an empty mold using three models; their electroformed direct oil heating model $(\mathrm{EDOH})$, a conventional oil heating model and a forced air convection model. Time to PIAT for the EDOH mold was $56 \%$ shorter than for the air forced convection mold and $55 \%$ shorter than for the conventional oil heated mold.

Experimental results for the EDOH mold showed good agreement with the CFD analysis. Thermal uniformity of the EDOH mold was, however, worse than in the air forced convection case. Since part wall thickness is proportional to the temperature at any point on the mold surface, this could negatively impact its uniformity.

\subsection{Mold surface enhancement}

Enhancement is achieved by fabricating protrusions onto the mold surface in order to improve convective heat transfer to and from the mold, thereby reducing heating and cooling times. Abdullah et al. [88] compared the heat transfer rates of a plain mold with molds having pyramid shaped roughness elements and square pins. Results (Table 2) showed considerable cycle time reductions for the surface enhanced molds when compared with the plain mold.

Liu and $\mathrm{Fu}$ [89] machined three sets of equal volume fins with; pin, rectangular, and triangular sections onto base plates and mechanically attached them to an aluminum mold. Temperature measurements taken during standard RM cycles (Table 2) showed a significant increase in cycle time reduction between the un-modified and surface enhanced molding regimes. The pin and triangular surface molds coincided in cycle time reduction values despite the former having a significantly larger surface area than the latter. This resulted from the full utilization of the triangular fin surfaces in the direction of rotation. In the pin 
Table 2. Cycle time reduction for surface enhanced molds from Abdullah and Liu

\begin{tabular}{|c|c|c|c|c|c|c|c|}
\hline \multirow{2}{*}{$\begin{array}{c}\text { Shot weight } \\
{[\mathrm{g}]}\end{array}$} & \multirow{2}{*}{$\begin{array}{c}\text { Part wall } \\
\text { thickness } \\
\text { [mm] }\end{array}$} & \multirow{2}{*}{$\begin{array}{c}\text { Rotational } \\
\text { speed } \\
\text { [rpm] }\end{array}$} & \multirow{2}{*}{$\begin{array}{c}\text { Oven } \\
\text { temperature } \\
{\left[{ }^{\circ} \mathrm{C}\right]}\end{array}$} & \multicolumn{3}{|c|}{$\begin{array}{c}\text { Cycle time reductions } \\
{[\%]}\end{array}$} & \multirow{2}{*}{ Reference } \\
\hline & & & & Pyramid & Pin & & \\
\hline- & 3.2 & - & \multirow{2}{*}{300} & 17 & 32 & & \multirow{5}{*}[88]{} \\
\hline- & 6,0 & - & & 19 & 28 & & \\
\hline- & 3.2 & - & \multirow{3}{*}{380} & 16 & \multicolumn{2}{|l|}{26} & \\
\hline- & 6,0 & - & & 20 & \multicolumn{2}{|l|}{25} & \\
\hline- & 9,0 & - & & 16 & \multicolumn{2}{|l|}{28} & \\
\hline & & & & Rectangular & Pin & Triangular & \\
\hline 150 & - & \multirow{3}{*}{12} & \multirow{3}{*}{270} & 11.18 & 13.93 & 14.56 & \multirow{3}{*}{ [89] } \\
\hline 200 & - & & & 11.37 & 15.51 & 14.94 & \\
\hline 250 & - & & & 12.10 & 14.09 & 14.81 & \\
\hline
\end{tabular}

enhanced mold, the pin surfaces located on the side opposite to the direction of air flow were partially obscured and thus not fully utilized.

\subsection{Pressurization}

As discussed earlier, mold pressurization in RM may be applied as a means to hasten bubble dissolution in the polymer melt $[54,60]$. A reduction in this curing period leads to a reduction in overall cycle time and lowered PIAT. Mold pressurization is also applied to reduce warpage $[37,90]$. Pressure is introduced into the mold during cooling to ensure constant contact of the polymer with the mold surface. Such conditions improve heat transfer through the mold wall from the polymer, resulting in shorter cooling times. Crawford et al. [30] observed an increase of approximately 11 to $18^{\circ} \mathrm{C} / \mathrm{min}$ in the cooling rate, with the introduction of pressurized air at room temperature.

\subsection{Internal cooling}

Internal cooling as a means to reduce the molding cycle time in the period between PIAT and de-molding was first suggested by Ramazzoti [91]. Subsequent authors attempted, with varying degrees of success, the application of compressed air [92], liquid nitrogen [93], liquid carbon dioxide $\left(\mathrm{CO}_{2}\right)$ [92] and water sprays $[6,34,35,92]$ as coolants. Among these coolants, compressed air and water sprays emerged as the most viable mediums for internal cooling. The other two methods, i.e. Liquid nitrogen and $\mathrm{CO}_{2}$, presented with concerns such as increased warpage due to steep in-mold pressure drops [93], complicated mold configurations and component failures due to excessively low temperatures [92]. A comprehensive review of these and other internal cooling techniques is given by Tan et al. in reference [94].

Khouri [92] attached two air movers to inlet and exhaust ports on the mold inner surface. The inlet port and air mover provided air into the mold while the exhaust port and air mover prevented pressure accumulation within the mold (Figure 6). The authors measured the effect of compressed air on the cooling time at inlet and exhaust air velocities of 3.6 and $2.4 \mathrm{~m} / \mathrm{s}$ respectively and manifold pressures of $0.1 \mathrm{MPa}$. They achieved a reduction of $19 \%$ in cooling time compared to a mold with no internal cooling. Increased air velocities and manifold pressures achieved improved reductions of up to $25 \%$ in cooling duration.

The convective heat transfer coefficient of evaporating water is approximately 1000 times greater than that of quiescent air. Therefore atomized sprays of water provide a highly efficient means of cooling the mold interiors in RM. McCourt and Kearns [6] delivered water sprays with an average droplet size of $50 \mu \mathrm{m}$ into the mold cavity using a pneumatic nozzle. At the end of heating, an opening on the mold wall enabled manual spray delivery for 40 seconds; after which external water cooling took over for the remainder of the duration until de-molding. The experiment achieved a $30 \%$ reduction in cooling duration as compared to an air cooled mold.

Abdullah et al. [95], used plain and surface enhanced molds, as well as a methodology, similar to their previous work [88] to examine the cycle reduction effects of a combination of physical techniques. They obtained optimal results by using a combination of surface enhanced molds, higher oven flow rates, internal mold pressure, and water spray cooling. The plain, 


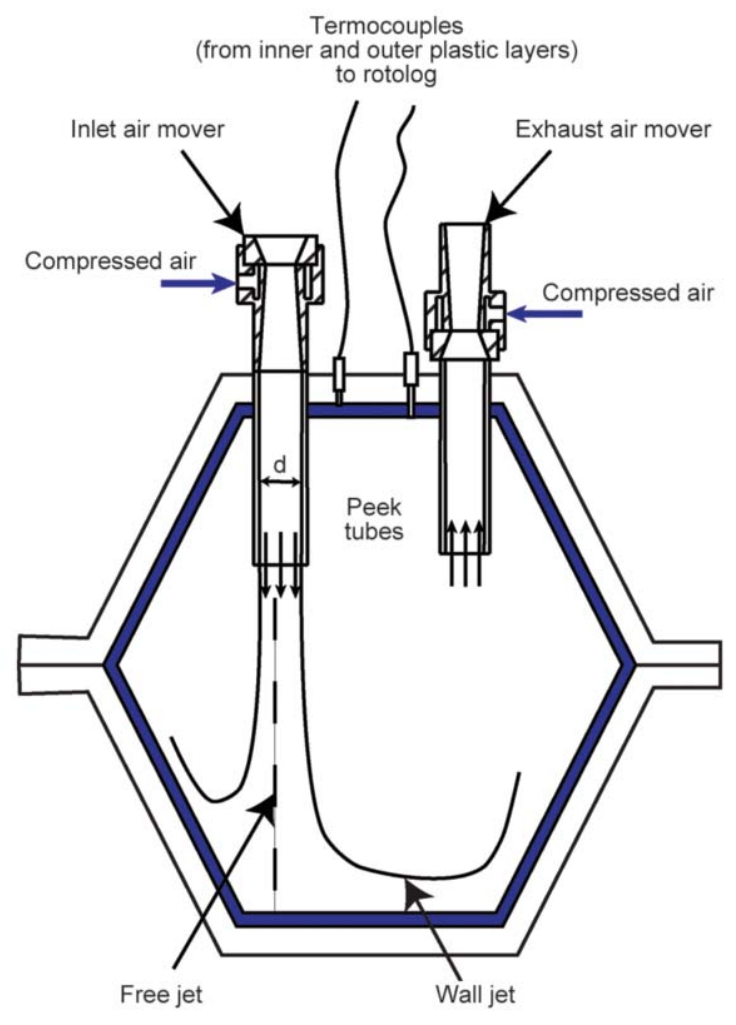

Figure 6. Internal cooling set up

roughness enhanced and pin molds produced cycle time reductions of 57,65 , and $70 \%$ respectively.

\section{Range of materials}

Due to the duration and temperature characteristics of RM, the polymers suitable for this process are fewer in number as compared to those available for most other polymer processing techniques. This has secured the position of PE as the main RM material; a position it has reinforced with its low cost and resistance to chemical and UV degradation. Nonetheless, materials other than PE are applied in RM, albeit with varying degrees of complexity. These include: PP, polycarbonate, polyamide, ethylene-vinyl acetate, ethylene butyl acrylate, polymethyl methacrylate, styrenics, cellulosics, polyurethanes (PU), silicones, unsaturated polyesters and epoxies. An in depth description of these RM materials and their properties is given in reference [96].

\subsection{Single site polymers}

The advent of SS polymers, alongside traditional ZN catalyzed polymers somewhat broadened the range of materials available for RM. However, taking into consideration that SS catalysts are suitable only for olefin polymerization; it is clear that these materials contribute minimally. Different grades of PE [24,
97-101] and PP [102] have, nonetheless, demonstrated their suitability to the RM process. For instance, experiments by Xin et al. [98] and later by Hay et al. [97] showed that under similar molding conditions SS PEs possessed; better mechanical properties, wider processing windows and higher bubble dissolution rates at lower temperatures than ZN catalyzed polymers.

\subsection{Thermotropic liquid crystal polymers}

Thermotropic liquid crystal polymers (TLCPs) exhibit both the characteristics of an amorphous polymer and a solid crystal when they are heated above either their glass transition temperature $\left(T_{\mathrm{g}}\right)$ or $T_{\mathrm{m}}$. They are especially attractive materials due to their; high tensile strength and moduli, excellent gas barrier properties, high resistance to a range of chemicals and good dimensional stability [103, 104].

Rangarajan et al. [105] studied the sinterability and rheology of a TLCP (Vectra B230), and determined that both were acceptable for RM. The TLCP moldings also possessed superior mechanical properties. However, the bulk density of the milled Vectra B230 powder was very low; which resulted in the lumping of its particles and led to higher porosity. The addition of various quantities of HDPE powder resulted in better particle coalescence and improved bubble removal.

Scribben and Baird [106] discovered that the low bulk density of TLCP powder resulted from a change in its morphology instigated by shearing forces during extrusion. These forces caused the liquid crystalline regions of the polymer orient themselves into fibrillar structures; which broke down into the resulting fibers on the TLCP particles upon milling. They improved the bulk density by melt extruding the TLCP with an immiscible polymer (PP); which they retrieved after quenching and powdering the mixture. The flow characteristics, particle coalescence and melt viscosity of the TLCP powder were acceptable for RM conditions. Melt densification, however, remained relatively poor and moldings made from the material possessed numerous surface pores. The authors attributed this to the aforementioned gas barrier properties of the polymer.

\subsection{Bio-polymers}

Bio-polymers possess enormous potential as materials not only for RM but for the entire plastics industry. The main advantage of these polymers is their 
environmental friendliness and to some extent biodegradability. They are, however, being held back by their high cost and brittleness. Also, due to their high zero shear viscosity RM of these polymers is very challenging.

Greco and coworkers $[78,107]$ investigated the sinterability of a PLLA and its suitability to RM. Experimental results enabled the formulation of three dimensionless numbers G1, G2 and G3; which were representative of the onset of sintering, end of sintering and onset of degradation respectively. The evolution of these numbers generated Continuous Heating Transformation (CHT) curves; which showed that a processing window wide enough for RM could be achieved only with the application of slower heating rates. Further investigations into the effect of plasticizer showed a substantial reduction in the temperature of coalescence ( $\left.T_{\text {coalesce }}\right)$ due to reduced viscosity; this was, however, accompanied by a drastic lowering of the temperature at the onset of degradation $\left(T_{\text {on, deg }}\right)$ by almost $100 \mathrm{~K}$. No apparent correlation could be found between the type of plasticizer and onset of degradation.

\subsection{Liquid plastic systems}

The liquid plastics systems (LPSs) applied in RM fall into two distinct groups: reactive and non-reactive. Reactive LPSs undergo in-situ polymerization in $\mathrm{RM}$ and require catalysts and or activators to enable reasonable reaction times. These reactive processes, give rise to the term reactive RM (RRM). In RM reactive LPSs can further be classified, according to their polymerization mechanisms as: thermosetting (TS) systems, which include silicones, polyurethanes (PU) and unsaturated polyesters (UP); and thermoplastic (TP) systems which are made up predominantly of caprolactam (CL) $[1,108]$, and to a lesser degree laurolactam $[109,110]$.

The polymerization reaction for TS LPSs occurs under the action of a catalyst at either the functional end groups or by the opening up of double bonds along the polymer backbone [1]. The process results in the formation of intractable three dimensional crosslinked polymer networks. TS systems such as silicones and UP may require some heating; while highly reactive systems such as PU are usually reacted in a cold mold.

The in-situ RRM of lactams, which make up the reactive TP group of LPSs, involves the ring opening polymerization of a low viscosity precursor by the action of heat, chain initiators and catalysts. This process occurs in three distinct steps:

(i) the formation of anions,

(ii) the formation of a complex from the combination of activator and catalyst and

(iii) polymerization through the action of anions, with new anions formed during the addition of each consecutive monomer [111].

The non-reactive classification for RM LPSs is reserved for a single polymer system, PVC plastisols. PVC plastisols are manufactured by suspending $0.1-$ 0.2 micron sized particles in a plasticizer [1]. During processing via RM, the polymer system undergoes a number of changes with increasing mold temperature. As the glass transition temperature of the polymer approaches, the PVC particles absorb the plasticizer and begin to swell. This continues until all the plasticizer has been absorbed. At this stage the polymer that is deposited on the mold wall lacks cohesion between its particles and is not structurally stable. Fusion begins when the PVC reaches temperatures of approximately $120^{\circ} \mathrm{C}$; and when temperatures increases further to $190^{\circ} \mathrm{C}$ the PVC plastisol becomes fully densified [112].

The processing of liquid systems by RM is less tedious than that of solid plastics. This is because, unlike the latter, liquid RM is characterized by; a short heating duration (approximately 15 minutes) with little cooling required, a low material initial viscosity, and a wider selection of applicable materials. LPSs have a long history of application in RM; beginning with PVC plastisols since the early 1940s, followed later by caprolactams and PU in the 1950s and 1970s respectively $[113,114]$. Subsequent works investigated and attempted to resolve the problems inherent to these materials, such as uneven material distribution and part porosity [108, 115-120].

Throne and Gianchandani [120], identified four flow regimes for a reactive polyester resin: cascading, rimming, stable hydrocyst, and solid body rotation (SBR) (Figure 7). During cascading flow a volume of polymer left the pool at the bottom of the mold and at a certain rotational angle flowed back down. With increasing time, the rise in viscosity due to polymerization caused the polymer volume that left the pool to stick to the mold wall, giving rise to the rimming flow. Increased viscosity gave rise to rings of material also known as hydrocysts; which, due to rising viscosity, disappeared after a short while leaving a solid body rotation (SBR). The authors determined 


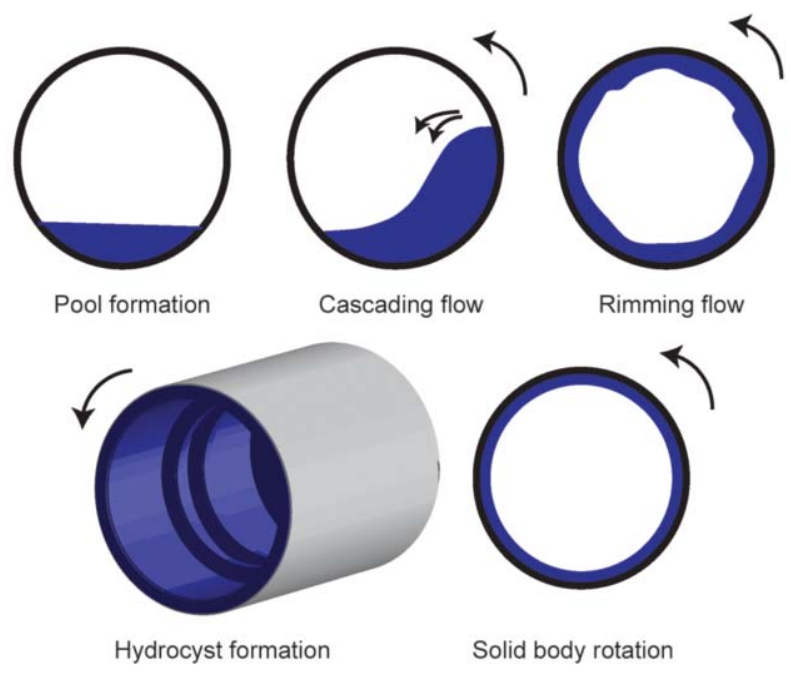

Figure 7. flow regimes typical for LPSs

that SBR occurred at a certain critical value for viscosity given by Equation (23):

$\mu_{\mathrm{SBR}}=\frac{0,7652 \rho d}{R \omega^{1.5}}$

where $\mu_{\mathrm{SBR}}$ viscosity at which solid-body rotation occurs, $\rho$ fluid density, $d$ wall part thickness, $\omega$ angular rotation speed, and $R$ cylinder radius.

To ensure fault free moldings SBR should occur just before the steep rise in the viscosity profile which signifies the start of gelation. Otherwise, the hydrocysts formed will freeze onto the part wall, resulting in uneven part thickness. Harkin-Jones and Crawford [115] confirmed this in a cylindrical mold using the viscosity profile of a fault free Nyrim molding; for which they compared the theoretical SBR value and the observed point of gelation. Further, in order to extend the fault free operating region they, in agreement with Equation (23), suggested the following: increasing rotation speed, decreasing wall thickness (or producing the molding in double shots) and altering the viscosity profile. The last suggestion resulted from investigations into the effect of hollow glass microspheres; which when, added to Nyrim (up to $7 \%$ by weight), extended its fault free operating region. The glass microspheres reduced the rate at which the temperature profile increased; which in turn led to a more gradual viscosity profile.

Indeed initial viscosity and rate of viscosity change are the variables that most significantly affect final part quality. When square molds are used, LPSs having lower initial viscosity alongside rapidly increasing viscosity profiles tend to produce parts with the most number of defects $[115,117,119]$. This is because irregularities in wall thickness that arise from flow disturbances (corners) are more likely to freeze into the moldings during gelation. Similarly bubbles in moldings may arise when the corners pick up quantities of material which they cannot support. The material subsequently drips down from the overhead positions back into the pool (re-pooling) where it traps air bubbles [115]. To counteract the effect of these disturbances, slow rotational speeds are recommended for low viscosity materials $[108,115]$. On the other hand, too high an initial viscosity can lead to insufficient mold coverage. Harkin-Jones and Crawford [115] applied increased mold temperatures of up to $70^{\circ} \mathrm{C}$ in order to lower the initial viscosity of PU and obtain a molding of suitable quality. This increased temperature, however, necessitated the use of higher rotational speeds to balance out the increased reaction viscosity.

Initial mold temperatures must, therefore, also be regulated to achieve optimum molding conditions. The rate of change in viscosity profile for LPSs increases with increasing mold temperature $[108,117]$. Mold temperatures do not directly affect the viscosity increase, They do, on the other hand, act to reduce the induction time and or increase the polymerization rates of LPSs [117]. Initial mold temperature also affects the crystallization mechanism of thermoplastic LPSs $[108,116,117]$. At high processing temperatures $\left(>150^{\circ} \mathrm{C}\right)$, Harkin-Jones and Crawford [116] observed a sharp drop in the level of crystallinity for Nyrim; which they attributed to increased branching and chain entanglement resulting from increased molecular weight at these temperatures. Similar results were obtained at low mold temperatures as a result of concurrent polymerization and crystallization events; due to which the reactive chain ends became trapped in the solid crystals before polymerization was complete.

Barhoumi et al. [108] identified two distinct isotherms for polymerization and crystallization events for Caprolactam at higher temperatures $\left(170-180^{\circ} \mathrm{C}\right)$. At lower temperatures $\left(150-160^{\circ} \mathrm{C}\right)$ only a single isotherm existed, showing that the two events occurred simultaneously. Both works $[108,116]$ observed that for LPSs, the number of crystal nucleation sites increased, and spherulite sizes were generally smaller; which was due to polymerization and crystallization events that occurred below $T_{\mathrm{m}}$ and $T_{\mathrm{c}}$ of the final polymer PA6. Barhoumi and coworkers [108, 117], further identified a relationship between activator/ 
catalyst concentration and the polymerization induction time for reactive LPSs. As expected higher concentrations of activator/catalyst reduced induction times and increased the reaction rates.

\section{Conclusions}

Amongst the theoretical models evaluated, the fixed domain techniques yield the most reliable results [10, 20-26]. Enthalpy based models; specifically the semi empirical approaches suitably represent the melting and crystallization events during the RM cycle [23-26]. An issue of concern however is their reliance on experimental data which can be severely limiting when such is unavailable. Nonetheless, these models enable the accurate prediction of the RM process and optimization of its parameters. Similarly advances in process control, especially advances in the sphere of automatic control for the RM process, may significantly improve the reproducibility of components over numerous runs [31-33].

Surface finish in RM is evaluated primarily in terms of the prevalence of porosity $[38,57,60]$, severity of degradation [36] and warpage levels [37, 79, 80]. This previous work provides valuable insight into the bubble dissolution, degradation and warpage mechanisms; and perhaps more importantly the variables that affect them. Pressurized molding conditions present the greatest potential for eradicating surface defects in RM. Pressure increases bubble dissolution rates $[54,59,60]$; which lowers PIAT resulting in reduced polymer degradation. Pressure also keeps the polymer in contact with the mold surface. This not only reduces warpage, but improves heat transfer through the mold wall as well, which shortens cycle times [30]. In addition this improved contact can also result in high quality exteriors if highly polished mold surfaces are used.

LPSs, in a similar manner, present a potential solution to some of the problems encountered in RM. Because they require only short heating durations with little cooling, the application of LPSs can result in reduced cycle times while simultaneously providing a wider range of applicable polymers for the process. Also, LPSs with their low initial viscosity $\left(\eta<10^{-2} \mathrm{~Pa} \cdot \mathrm{s}\right)$ and good surface reproducibility, as well as the low over pressures sufficient for good fiber impregnation, are extremely attractive structural molding materials [121]. The potential for LPSs may however be hindered by the shortage of predictive thermal and mold filling models for these materials in the RM process.

\section{Acknowledgements}

This research was funded by the National Key Research and Development Plan (grant numbers 2016YFB0302002 and 2016YFB0302003) and the China Scholarship Council (grant number 2013404006). Special thanks to Wenling Rising Sun Rotational Moulding Technology Co., Ltd. for graciously providing their technical assistance during course of this work.

\section{References}

[1] Crawford R. J., Throne J. L.: Rotational moulding of plastics. Research Studies Press, Somerset (1996).

[2] Khan W. A., Methven J.: Control of the uniformity of direct electrical heating for rotational moulding. in 'Proceedings of the $36^{\text {th }}$ International MATADOR Conference. London, UK' Vol 1, 87-90 (2010).

[3] McCourt M. P., Kearns M. P., Hanna P. R.: The adaption of microwave heating to the rotational moulding process. in 'SPE-ANTEC Annual Technical Conference. Orlando, USA' Vol 2, 1274-1278 (2010).

[4] Von Kries K.: System, method and apparatus for solar heated manufacturing. U.S. Patent 8662877, USA (2014).

[5] Memering L. J., Schott S.: Rotational molding process. U.S. Patent 3514508 A, USA (1970).

[6] McCourt M. P., Kearns M. P.: The development of internal water cooling techniques for the rotational moulding process. in 'SPE-ANTEC Annual Technical Conference. Chicago, USA' Vol 4, 1961-1965 (2009).

[7] Marrero M. D., Hernández P., Suárez L., Pestana D., Benítez A., Martín J., Rivero S., Calero E.: Rotational molding applied to the manufacturing of blades of small wind turbine. in 'ASME $201412^{\text {th }}$ Biennial Conference on Engineering Systems Design and Analysis. Copenhagen, Denmark' Vol 3, 1-5 (2014).

[8] Sarrabi S., Colin X., Tcharkhtchi A.: Kinetic modeling of polypropylene thermal oxidation during its processing by rotational molding. Journal of Applied Polymer Science, 118, 980-996 (2010). https://doi.org/10.1002/app.32459

[9] Crawford R. J.: Recent advances in the manufacture of plastic products by rotomoulding. Journal of Materials Processing Technology, 56, 263-271 (1996). https://doi.org/10.1016/0924-0136(95)01840-9

[10] Lim K. K., Ianakiev A.: Modeling of rotational molding process: Multi-layer slip-flow model, phase-change, and warpage. Polymer Engineering and Science, 46, 960969 (2006).

https://doi.org/10.1002/pen.20481

[11] Gogos G., Olson L. G., Liu X., Pasham V. R.: New models for rotational molding of plastics. Polymer Engineering and Science, 38, 1387-1398 (1998). https://doi.org/10.1002/pen.10309 
[12] Rao M. A., Throne J. L.: Principles of rotational molding. Polymer Engineering and Science, 12, 237-264 (1972).

https://doi.org/10.1002/pen.760120402

[13] Throne J. L.: Rotational molding heat transfer-an update. Polymer Engineering and Science, 16, 257-264 (1976).

https://doi.org/10.1002/pen.760160407

[14] Crawford R. J., Scott J. A.: An experimental study of heat transfer during rotational moulding of plastics. Plastics, Rubber and Composites Processing and Applications, 5, 239-248 (1985).

[15] Xu L., Crawford R. J.: Computer simulation of the rotational moulding process. Plastics, Rubber and Composites Processing and Applications, 21, 257-273 (1994).

[16] Bawiskar S., White J. L.: Simulation of heat transfer and melting in rotational molding. International Polymer Processing, 10, 62-67 (1995).

https://doi.org/10.3139/217.950062

[17] Gogos G., Liu X., Olson L. G.: Cycle time predictions for the rotational molding process with and without mold/part separation. Polymer Engineering and Science, 39, 617-629 (1999).

https://doi.org/10.1002/pen.11451

[18] Nugent P. J., Crawford R. J., Xu L.: Computer prediction of cycle times during rotational molding of plastics. Advances in Polymer Technology, 11, 181-191 (1992). https://doi.org/10.1002/adv.1992.060110302

[19] Crawford R. J., Nugent P.: Computer simulation of the rotational moulding process for plastics. Plastics and Rubber Processing and Applications, 11, 107-124 (1989).

[20] Lim K. K., Ianakiev A.: Two-dimensional slip-flow model of rotational molding. in 'SPE-ANTEC Annual Technical Conference. Chicago, USA' Vol 1, 892-896 (2004).

[21] Lim K. K., Ianakiev A.: Numerical studies of the phase change and warpage under various process conditions for rotational molding. in 'SPE-ANTEC Annual Technical Conference. Chicago, USA' Vol 1, 897-901 (2004).

[22] Banerjee S., Yan W., Bhattacharyya D.: Modeling of heat transfer in rotational molding. Polymer Engineering and Science, 48, 2188-2197 (2008).

https://doi.org/10.1002/pen.21164

[23] Greco A., Maffezzoli A., Vlachopoulos J.: Simulation of heat transfer during rotational molding. Advances in Polymer Technology, 22, 271-279 (2003).

https://doi.org/10.1002/adv.10055

[24] Bellehumeur C. T., Medina A., Xu H.: Dimensional stability of single-site ethylene copolymers in rotational molding. Polymer Engineering and Science, 49, 1400 1409 (2009).

https://doi.org/10.1002/pen.21017

[25] Xu H., Bellehumeur C. T.: Modeling the morphology development of ethylene copolymers in rotational molding. Journal of Applied Polymer Science, 102, 5903 5917 (2006).

https://doi.org/10.1002/app.25092
[26] Xu H., Bellehumeur C. T.: Thermal residual stress development for semi-crystalline polymers in rotational molding. Polymer Engineering and Science, 48, 283291 (2008).

https://doi.org/10.1002/pen.20887

[27] Tcharkhtchi A., Perrot E., Chinesta F.: Simulation of thermal phenomena on the interface molten polymer/ powder polymer during rotational molding. International Polymer Processing, 19, 296-302 (2004). https://doi.org/10.3139/217.1835

[28] Nugent P. J.: Theoretical and experimental studies of heat transfer during rotational molding process. $\mathrm{PhD}$. Thesis, Mechanical and Manufacturing Engineering, Queen's University, Belfast (1990).

[29] Crawford R J., Nugent P J.: A new process control system for rotational moulding. Plastics, Rubber and Composites Processing and Applications, 17, 23-31 (1992).

[30] Crawford R. J., Spence A. G., Cramez M. C., Oliveira M. J.: Mould pressure control in rotational moulding. Proceedings of the Institution of Mechanical Engineers Part B: Journal of Engineering Manufacture, 218, 1683-1693 (2004).

https://doi.org/10.1177/095440540421801204

[31] Abu-Al-Nadi D. I., Abu-Fara D. I., Rawabdeh I., Crawford R. J.: Control of rotational molding using adaptive fuzzy systems. Advances in Polymer Technology, 24, 266-277 (2005). https://doi.org/10.1002/adv.20047

[32] Nugent P. J.: Rotational molding apparatus and method using infrared thermometry. U.S. Patent 6036897 A, USA (2000).

[33] Nugent P., Little E., Peev G.: Use of non-contact temperature sensing in extending process control for rotational molding. in 'SPE-ANTEC Annual Technical Conference. Toronto, Canada', Vol 3, 3200-3204 (1997).

[34] Tan S. B., Hornsby P. R., McAfee M. B., Kearns M. P., McCourt M. P.: Water spray cooling of polymers. Polymer Engineering and Science, 52, 1069-1080 (2012). https://doi.org/10.1002/pen.22173

[35] Tan S. B.: Accelerated cooling of thermoplastics in rotational moulding. PhD Thesis, Mechanical and Aerospace Engineering, Queen's University Belfast (2010).

[36] Cramez M. C., Oliveira M. J., Crawford R. J.: Optimisation of rotational moulding of polyethylene by predicting antioxidant consumption. Polymer Degradation and Stability, 75, 321-327 (2002).

https://doi.org/10.1016/S0141-3910(01)00234-8

[37] Liu S-J., Ho C-Y.: Factors affecting the warpage of rotationally molded parts. Advances in Polymer Technology, 18, 201-207 (1999). https://doi.org/10.1002/(SICI)10982329(199923)18:3<201::AID-ADV1>3.0.CO;2-N

[38] Spence A. G., Crawford R. J.: The effect of processing variables on the formation and removal of bubbles in rotationally molded products. Polymer Engineering and Science, 36, 993-1009 (1996). https://doi.org/10.1002/pen.10487 
[39] Frenkel J.: Viscous flow of crystalline bodies under the action of surface tension. Journal of Physics, 9, 385391 (1945).

[40] Eshelby J. D.: Seminar on the kinetics of sintering. Metals Transactions, 185, 806-807 (1949).

[41] Kingery W. D., Berg M.: Study of the initial stages of sintering solids by viscous flow, evaporation-condensation, and self-diffusion. Journal of Applied Physics, 26, 1205-1212 (1955).

https://doi.org/10.1063/1.1721874

[42] Kuczynski G. C.: Study of the sintering of glass. Journal of Applied Physics, 20, 1160-1163 (1949). https://doi.org/10.1063/1.1698291

[43] Kuczynski G. C., Zaplatynskyj I.: Sintering of glass. Journal of the American Ceramic Society, 39, 349-350 (1956). https://doi.org/10.1111/j.1151-2916.1956.tb15601.x

[44] Bellehumeur C. T.: Polymer sintering and its role in rotational molding. PhD Thesis, McMaster University, Hamilton (1997).

[45] Pokluda O., Bellehumeur C. T., Vlachopoulos J.: Modification of frenkel's model for sintering. American Institute of Chemical Engineering Journal, 43, 3253-3256 (1997).

https://doi.org/10.1002/aic.690431213

[46] Narkis M.: Sintering behavior of poly(methyl methacrylate) particles. Polymer Engineering and Science, 19, 889-892 (1979). https://doi.org/10.1002/pen.760191302

[47] Bellehumeur C. T., Bisaria M. K., Vlachopoulos J.: An experimental study and model assessment of polymer sintering. Polymer Engineering and Science, 36, 2198 2207 (1996). https://doi.org/10.1002/pen.10617

[48] Lontz J. F.: Sintering of polymer materials. in 'Sintering and plastic deformation: Proceedings of the first symposium on fundamental phenomena in the material sciences. Boston, USA' Vol 1, 25-47 (1964).

[49] Bellehumeur C. T., Kontopoulou M., Vlachopoulos J.: The role of viscoelasticity in polymer sintering. Rheologica Acta, 37, 270-278 (1998).

https://doi.org/10.1007/s003970050114

[50] Hamidi A., Farzaneh S., Nony F., Ortega Z., Khelladi S., Monzon M., Bakir F., Tcharkhtchi A.: Modelling of sintering during rotational moulding of the thermoplastic polymers. International Journal of Material Forming, 9, 519-530 (2016).

https://doi.org/10.1007/s12289-015-1239-6

[51] Nguyen H. T., Cosson B., Lacrampe M. F., Krawczak P.: Numerical simulation on the flow and heat transfer of polymer powder in rotational molding. International Journal of Material Forming, 8, 423-438 (2015). https://doi.org/10.1007/s12289-014-1185-8

[52] Olinek J., Anand C., Bellehumeur C. T.: Experimental study on the flow and deposition of powder particles in rotational molding. Polymer Engineering and Science, 45, 62-73 (2005).

https://doi.org/10.1002/pen.20230
[53] Greco A., Maffezzoli A.: Powder-shape analysis and sintering behavior of high-density polyethylene powders for rotational molding. Journal of Applied Polymer Science, 92, 449-460 (2004). https://doi.org/10.1002/app.20012

[54] Kontopoulou M., Vlachopoulos J.: Bubble dissolution in molten polymers and its role in rotational molding. Polymer Engineering and Science, 39, 1189-1198 (1999). https://doi.org/10.1002/pen.11505

[55] Progelhof R. C., Cellier G., Throne J.: New technology in rotational molding: Powder densification. in 'SPEANTEC Annual Technical Conference. San Francisco, USA', Vol 28, 627-629 (1982).

[56] Kelly P. Y.: Microscopic examination of rotomolded polyethylene. Du Pont, Toronto (1981).

[57] Crawford R. J., Scott J. A.: The formation and removal of gas bubbles in a rotational moulding grade of polyethylene. Plastics and Rubber Processing and Application, 7, 85-99 (1987).

[58] Crawford R. J., Xu L.: Analysis of the formation and removal of gas bubbles in rotationally moulded thermoplastics. Journal of Materials Science, 28, 20672074 (1993). https://doi.org/10.1007/BF00367563

[59] Gogos G.: Bubble removal in rotational molding. Polymer Engineering and Science, 44, 388-394 (2004). https://doi.org/10.1002/pen.20035

[60] Spence A. G., Crawford R. J.: Removal of pinholes and bubbles from rotationally moulded products. Proceedings of the Institution of Mechanical Engineers Part B: Journal of Engineering Manufacture, 210, 521-533 (1996). https://doi.org/10.1243/pime proc 1996_210_151_02

[61] Spence A. G.: Analysis of bubble formation and removal in rotationally moulded products. $\mathrm{PhD}$ Thesis, The Queen's University of Belfast, Belfast (1994).

[62] Gijsman P.: Review on the thermo-oxidative degradation of polymers during processing and in service. ePolymers, no.065 (2008). https://doi.org/10.1515/epoly.2008.8.1.727

[63] Yang R., Zhao J., Liu Y.: Oxidative degradation products analysis of polymer materials by pyrolysis gas chromatography-mass spectrometry. Polymer Degradation and Stability, 98, 2466-2472 (2013). https://doi.org/10.1016/j.polymdegradstab.2013.05.018

[64] Oliveira M. J., Cramez M. C., Crawford R. J.: Structure-properties relationships in rotationally moulded polyethylene. Journal of Materials Science, 31, 22272240 (1996). https://doi.org/10.1007/BF01152932

[65] Colin X., Verdu J.: Polymer degradation during processing. Comptes Rendus Chimie, 9, 1380-1395 (2006). https://doi.org/10.1016/j.crci.2006.06.004

[66] Sarrabi S., Lacrampe M-F., Krawczak P.: Phosphorous antioxidants against polypropylene thermal degradation during rotational molding-kinetic modeling. Journal of Applied Polymer Science, 132, 41285/1-41285/11 (2014). https://doi.org/10.1002/app.41285 
[67] Bolland J. L.: Kinetic studies in the chemistry of rubber and related materials. I. The thermal oxidation of ethyl linoleate. Proceedings of the Royal Society Series A: Mathematical Physical and Engineering Sciences, 186, 218-236 (1946).

https://doi.org/10.1098/rspa.1946.0040

[68] Oliveira M. J., Botelho G.: Degradation of polyamide 11 in rotational moulding. Polymer Degradation and Stability, 93, 139-146 (2008).

https://doi.org/10.1016/j.polymdegradstab.2007.10.004

[69] Fairgrieve S.: Degradation and stabilisation of aromatic polyesters. Smithers Rapra, Shropshire (2009).

[70] Botelho G., Queirós A., Gijsman P.: Thermooxidative studies of poly(ether-esters) 1. Copolymer of poly(butylene terephthalate) and poly(ethylene oxide). Polymer Degradation and Stability, 67, 13-20 (2000). https://doi.org/10.1016/S0141-3910(99)00109-3

[71] Bacalogulu R., Kaufhold J., Sander H. J.: PVC stabilizers. in 'Plastics additive handbook' (ed.: Zweifel H.) Hanser, Munich, Vol 1, 428-446 (2001).

[72] Kovařík P., Klein E., Valko L.: Kinetic study of action of additives in poly(vinyl chloride) stabilizer systems i. Sterically hindered phenolic antioxidants. Chemical Papers, 51, 245-251 (1997).

[73] Gijsman P.: Polymer stabilization. in 'Applied plastics engineering handbook' (ed.: Kutz M.) William Andrew Publishing, Oxford, Vol 2, 375-399 (2011). https://doi.org/10.1016/B978-1-4377-3514-7.10021-2

[74] Grassie N., Scott G.: Polymer degradation and stabilization. Cambridge University Press, Cambridge (1988).

[75] Denisov E.: A theoretical approach to the optimization of antioxidant action. in 'Mechanisms of polymer degradation and stabilisation' (ed.: Scott G.) Elsevier, Amsterdam, Vol 1, 1-22 (1990).

[76] Oliveira M. J., Cramez M. C.: Rotational molding of polyolefins: Processing, morphology, and properties. Journal of Macromolecular Science Part B, 40, $457-$ 471 (2001). https://doi.org/10.1081/MB-100106170

[77] Jimenez A., Lopez J., Torre L., Kenny J. M.: Kinetic analysis of the thermal degradation of PVC plastisols. Journal of Applied Polymer Science, 73, 1069-1079 (1999).

https://doi.org/10.1002/(SICI)10974628(19990808)73:6<1069::AID-APP26>3.0.CO;2-K

[78] Greco A., Maffezzoli A., Forleo S.: Sintering of PLLA powders for rotational molding. Thermochimica Acta, 582, 59-67 (2014). https://doi.org/10.1016/j.tca.2014.03.005

[79] Bawiskar S., White J. L.: Comparative study of warpage, global shrinkage, residual stresses, and mechanical behavior of rotationally molded parts produced from different polymers. Polymer Engineering and Science, 34, 815-820 (1994).

https://doi.org/10.1002/pen.760341006
[80] Pop-Iliev R., Park C. B., Lee K. H.: The potentials for processing metallocene pe grades in rotational molding. in 'Proceedings of PPS-18, International Conference of the Polymer Processing Society. Guimaraes, Portugal' p.6 (2002).

[81] Glomsaker T., Larsen Å., Andreassen E., Ommundsen E.: Experimental and numerical investigation of warpage of semicrystalline polymers in rotational molding. Polymer Engineering and Science, 45, 945-952 (2005). https://doi.org/10.1002/pen.20348

[82] Nagy T., White J. L.: The effect of colorants on the properties of rotomolded polyethylene parts. Polymer Engineering and Science, 36, 1010-1018 (1996).

https://doi.org/10.1002/pen.10488

[83] Glomsaker T., Hinrichsen E. L., Larsen Å., Doshev P., Ommundsen E.: Warpage-crystallinity relations in rotational molding of polypropylene. Polymer Engineering and Science, 49, 523-530 (2009).

https://doi.org/10.1002/pen.21322

[84] Kolmogorov A. N.: On the statistics of the crystallization process in metals. Bulletin of the Academy of Sciences of the USSR, 1, 355-359 (1937).

[85] Avrami M.: Granulation, phase change, and microstructure kinetics of phase change. Journal of Chemical Physics, 9, 177-184 (1941).

https://doi.org/10.1063/1.1750872

[86] Evans U. R.: The laws of expanding circles and spheres in relation to the lateral growth of surface films and the grain-size of metals. Transactions of the Faraday Society, 41, 365-374 (1945).

https://doi.org/10.1039/TF9454100365

[87] Monzón M. D., Bordón P., Benítez A. N., Kearns M., Hernández P. M., Marrero M. D.: Global efficiency of innovative rotational mold directly heated by thermal fluid. Polymer Engineering and Science, 52, 19982005 (2012).

https://doi.org/10.1002/pen.23139

[88] Abdullah M. Z., Bickerton S., Bhattacharyya D.: Rotational molding cycle time reduction through surfaceenhanced molds Part B: Experimental study. Polymer Engineering and Science, 47, 1420-1429 (2007). https://doi.org/10.1002/pen.20834

[89] Liu S-J., Fu K-H.: Effect of enhancing fins on the heating/cooling efficiency of rotational molding and the molded product qualities. Polymer Testing, 27, 209220 (2008).

https://doi.org/10.1016/j.polymertesting.2007.10.004

[90] Chen C. H., White J. L., Ohta Y.: Mold pressurization as a method to reduce warpage in rotational molding of polyethylene. Polymer Engineering and Science, 30, 1523-1528 (1990). https://doi.org/10.1002/pen.760302306

[91] Ramazzotti D.: Rotational molding. in 'Plastics products design handbook' (ed.: Miller E.) Marcel Dekker, New York, Vol 1, 75-104 (1983). 
[92] Khouri R. M.: Reducing cycle times in rotational molding of plastics: A theoretical and experimental analysis. PhD Thesis in Mechanical and Manufacturing Engineering, The Queen's University of Belfast, Belfast (2004).

[93] O’Neill S. P.: Analysis of cooling in rotational moulding. $\mathrm{PhD}$ Thesis, Mechanical and Manufacturing Engineering, The Queen's University of Belfast, Belfast (1999).

[94] Tan S. B., Hornsby P. R., McAfee M. B., Kearns M. P., McCourt M. P.: Internal cooling in rotational molding - A review. Polymer Engineering and Science, 51, 1683-1692 (2011). https://doi.org/10.1002/pen.21973

[95] Abdullah M. Z., Bickerton S., Bhattacharyya D., Crawford R. J., Harkin-Jones E.: Rotational molding cycle time reduction using a combination of physical techniques. Polymer Engineering and Science, 49, 1846-1854 (2009). https://doi.org/10.1002/pen.21260

[96] Crawford R. J., Throne J. L.: Rotational molding technology. William Andrew Publishing, New York (2002).

[97] Hay H., Weber M., Donaldson R., Gibbons I., Bellehumeur C.: Single site polyethylene resins with enhanced processability for rotational molding applications. in 'SPE-ANTEC Annual Technical Conference. Chicago, USA' Vol 1, 865-869 (2004).

[98] Xin W., Harkin-Jones E. H., Crawford R. J., Fatnes AM.: Rotational moulding of metallocene polyethylenes. Plastics, Rubber and Composites, 29, 340-348 (2000). https://doi.org/10.1179/146580100101541148

[99] Pick L. T., Harkin-Jones E., Oliveira M. J., Cramez M. C.: The effect of cooling rate on the impact performance and dynamic mechanical properties of rotationally molded metallocene catalyzed linear low density polyethylene. Journal of Applied Polymer Science, 101, 1963-1971 (2006).

https://doi.org/10.1002/app.23709

[100] Archer E., Harkin-Jones E., Kearns M. P., Fatnes A-M.: The rotational molding characteristics of metallocene polyethylene skin/foam structures. Journal of Cellular Plastics, 43, 491-504 (2007).

https://doi.org/10.1177/0021955x07081349

[101] Archer E., Harkin-Jones E., Kearns M. P., Fatnes A. M.: Processing characteristics and mechanical properties of metallocene catalyzed linear low-density polyethylene foams for rotational molding. Polymer Engineering and Science, 44, 638-647 (2004). https://doi.org/10.1002/pen.20058

[102] Sarrabi S., Boyer S. A. E., Lacrampe M. F., Krawczak P., Tcharkhtchi A.: Metallocene polypropylene crystallization kinetic during cooling in rotational molding thermal condition. Journal of Applied Polymer Science, 130, 222-233 (2013).

https://doi.org/10.1002/app.39035
[103] Cox M. K.: The application of liquid crystal polymer properties. Molecular Crystals and Liquid Crystals, 153, 415-422 (1987). https://doi.org/10.1080/00268948708074556

[104] Chiou J., Paul D.: Gas transport in a thermotropic liquid-crystalline polyester. Journal of Polymer Science Part B: Polymer Physics, 25, 1699-1707 (1987). https://doi.org/10.1002/polb.1987.090250811

[105] Rangarajan P., Huang J., Baird D.: Studies on the rotomolding of liquid crystalline polymers. in 'SPEANTEC Annual Technical Conference. Orlando, USA' Vol 1, 1338-1343 (2000).

[106] Scribben E., Baird D.: The rotational molding of a thermotropic liquid crystalline polymer. Polymer Engineering and Science, 45, 410-423 (2005). https://doi.org/10.1002/pen.20276

[107] Greco A., Maffezzoli A., Forleo S.: Rotational molding of bio-polymers. in 'Proceedings of PPS-29 International Conference of the Polymer Processing Society. Nuremberg, Germany', Vol 1593, 333-337 (2014).

[108] Barhoumi N., Maazouz A., Jaziri M., Abdelhedi R.: Polyamide from lactams by reactive rotational molding via anionic ring-opening polymerization: Optimization of processing parameters. Express Polymer Letters, 7, 76-87 (2012).

https://doi.org/10.3144/expresspolymlett.2013.7

[109] Rusu G., Rusu E.: Caprolactam-laurolactam (nylon 6/12) copolymers: Synthesis and characterization. High Performance Polymers, 16, 569-584 (2004). https://doi.org/10.1177/0954008304041720

[110] Rusu G., Rusu E., Leontie L., Rusu G. I.: Electrical DC conduction mechanism in some newly synthesized nylon 6/12 copolymers. Journal of Polymer Science Part B: Polymer Physics, 45, 794-799 (2007). https://doi.org/10.1002/polb.21084

[111] Luisier A., Bourban P-E., Månson J-A. E.: Time-temperature-transformation diagram for reactive processing of polyamide 12. Journal of Applied Polymer Science, 81, 963-972 (2001).

https://doi.org/10.1002/app.1518

[112] Werner A. C.: The resins. in 'Plastisols and organosols' (ed.: Sarvetnick H. A.) Van Nostrand Reinhold, New York, Vol 1, 46-57 (1972).

[113] Schmid E., Eder R.: Process for activated anionic lactam polymerization. U.S. Patent 5756647 A, USA (1999).

[114] Scott K. A.: Penn's PVC technology. Applied Science Publishers, Barking (1972).

[115] Harkin-Jones E., Crawford R. J.: Rotational molding of liquid plastic systems: An assessment of material moldability. Advances in Polymer Technology, 15, 71100 (1996).

https://doi.org/10.1002/(SICI) 1098 2329(199621)15:1<71::AID-ADV6>3.0.CO;2-H

[116] Harkin-Jones E., Crawford R. J.: Mechanical properties of rotationally molded nyrim. Polymer Engineering and Science, 36, 615-625 (1996). https://doi.org/10.1002/pen.10449 
[117] Barhoumi N., Lamnawar K., Maazouz A., Jaziri M., Abdelhedi R.: Reactive rotational molding process of PP/PA6 bilayer systems: Experimental investigations. International Journal of Material Forming, 1, 671-674 (2008).

https://doi.org/10.1007/s12289-008-0304-9

[118] Viale J., Nony F., Mazabraud P., Gérard J-F., Tcharkhtchi A., Doulin G.: Rotational moulding of thermosets: Understanding of a reactive forming process. International Journal of Material Forming, 1, 803-806 (2008). https://doi.org/10.1007/s12289-008-0257-z
[119] Lecocq E., Nony F., Tcharkhtchi A., Gérard J-F.: Block copolymer modified epoxy amine system for reactive rotational molding: Structures, properties and processability. in 'The $14^{\text {th }}$ International Esaform Conference on Material Forming: ESAFORM 2011. Belfast, United Kingdom', Vol 1353, 767-772 (2011).

[120] Throne J. L., Gianchandani J.: Reactive rotational molding. Polymer Engineering and Science, 20, 899-919 (1980).

https://doi.org/10.1002/pen.760201309

[121] Ó Máirtín P., McDonnell P., Connor M. T., Eder R., Ó Brádaigh C. M.: Process investigation of a liquid pa12/carbon fibre moulding system. Composites Part A: Applied Science and Manufacturing, 32, 915-923 (2001). https://doi.org/10.1016/S1359-835X(01)00005-7 